\title{
亚洲夏季风爆发早晚的新前兆信号: 冬季南极涛动
}

\author{
高辉, 刘芸芸, 王永光, 李维京 \\ 中国气象局国家气候中心, 北京 100081 \\ E-mail: gaohui@cma.gov.cn
}

2012-05-24 收稿, 2012-08-02 接受

国家重点基础研究发展计划(2012CB417205)、科技部国际合作项目(2009DFA23010)、公益性行业(气象)科研专项(GYHY200906018)、国家 科技支撑计划(2009BAC51B)和国家自然科学基金(41005037)资助

\begin{abstract}
摘要 亚洲夏季风最早于 5 月上旬和中旬分别在中南半岛和南海爆发. 统计分析的结果显 示，其爆发早晚的前兆信号最早可追溯至冬季南半球中、高纬度的大气环流的异常，即南 极涛动. 冬季南极涛动偏强会造成初春南半球中纬度地区副热带高压带偏强, 低纬地区赤 道辐合带加深, 从而使南半球中纬度和热带地区的气压梯度力加大, 促使 3 4 月份索马里 越赤道气流较早建立并偏强. 受科氏力作用, 索马里急流增强并越过赤道后, 赤道印度洋 西风也偏强, 有利于孟加拉湾和南海地区低层辐合的加强和对流的活跃, 并使西太平洋副 高偏弱且较早东撤出南海, 造成亚洲夏季风爆发偏早. 反之, 当冬季南极涛动偏弱时, 南 半球副热带和热带之间的气压梯度力偏小, 索马里越赤道气流偏弱, 赤道印度洋西风也偏 弱, 孟加拉湾和南海对流偏弱, 南海上空副高偏强且东撤时间偏晚, 亚洲夏季风爆发偏晚. 这一结果在过去研究成果基础上进一步拓延了基于南半球大气环流信号预测亚洲夏季风 的时效, 并可作为一个新的前兆信号在业务中应用.
\end{abstract}

关键词

亚洲夏季风

中南半岛

南海

南极涛动

索马里越赤道气流
南极涛动是南半球中、高纬度大气环流最主要的 模态, 反映了南半球副热带高压带和高纬度绕极低 压带之间气压场的“跷跷板式”反位相变化特征, 并 可在很大程度上表征南半球主要大气环流系统的异 常, 如南极极浴、极区和副热带西风急流以及马斯克 林高压和澳大利亚高压等. 虽然南极涛动的发现和 研究可追溯至近一个世纪以前 ${ }^{[1 ~ 5]}$, 但其对东亚夏季 气候的影响多限于 20 世纪 80 年代及之后, 且固于南 半球高纬度资料的缺乏, 早期研究主要讨论的是其 副热带分支, 尤其是马斯克林高压(马高)和澳大利亚 高压(澳高)季节和年际变化对东亚夏季风的影响. 陶 诗言等人 ${ }^{[6]}$ 和陈隆勋 ${ }^{[7]}$ 的研究发现, 东亚夏季风期间 环流纬向和经向交替变化与澳大利亚地区的环流变 化有密切关系. 王绍武等人 ${ }^{[8]}$ 也指出冬半球的冷空气 活动对夏半球夏季风发展有重要影响. 黄士松等人 ${ }^{[9]}$
和杨修群等人 ${ }^{[10]}$ 的研究进一步指出马高在南北半球 大气环流相互作用中起重要作用, 是东亚夏季风体 系关键成员. 何金海等人 ${ }^{[11]}$ 分析了南半球中纬度大 气环流准 40 天振荡对北半球夏季风环流的影响, 指 出南半球冷空气爆发后, 通过低频振荡的经向传播 首先加强马高和澳高及二者南侧的西风，导致高压 北侧东南信风加强, 并使越赤道气流加强, 从而使北 半球夏季风活跃. 而越赤道气流尤其是索马里急流 的加强将加强南半球向北半球的水汽输送, 从而显 著影响东亚夏季降水 ${ }^{[12]}$.

研究表明, 南半球高纬地区是南半球大气环流 季节变化最早开始的地区 ${ }^{[13]}$, 而且高纬地区绕极低 压带的变动可以通过南极涛动影响南半球副热带高 压带, 从而进一步影响东亚夏季风环流. 近年来的一 些研究陆续指出, 南极涛动对北半球大气环流和气

英文版见: Gao H, Liu Y Y, Wang Y G, et al. Precursory influence of the Antarctic Oscillation on the onset of Asian summer monsoon. Chin Sci Bull, 2012, 57, doi: $10.1007 / \mathrm{s} 11434-012-5455-\mathrm{x}$ 
候异常可产生重要影响并可作为前兆信号用于短期 气候预测. 春季南极涛动加强, 则马高和澳高加强, 夏季东亚长江流域至日本一带多雨. 南极涛动是除 ENSO 之外另一个能影响东亚夏季降水年际变化的 强信号 ${ }^{[14]}$. 而在南极涛动影响东亚气候异常的过程 中, 索马里越赤道气流发挥着重要的纽带作用, 其年 际变化与东亚沿岸异常波列有非常好的对应关系. 当索马里越赤道气流偏强(弱)时, 夏季我国长江以南 降水易偏少 $(\text { 多 })^{[12]}$.

最近, 范可和王会军 ${ }^{[15]}$ 对南极涛动影响我国气 候异常做了大量研究, 发现南极涛动强年不利于东 亚冬春两季冷空气的活动. 通过平均经圈环流分析 发现, 在南极涛动异常年有从南极到北极分布的经 向遥相关, 并且该遥相关具有正压结构. 此遥相关冬 季在欧亚地区显著, 春季在太平洋地区显著. 局地经 向遥相关是冬、春两季中南北半球中高纬大气环流相 互作用的一个可能途径. 数值试验的结果也验证了 这一结论 ${ }^{[16]}$, 即冬、春季节南极涛动异常时两半球高 纬间的经向遥相关存在, 通过南极涛动的加强引起 北半球高纬环流异常和欧亚西风加强, 以及亚洲北 部地表气温和 $850 \mathrm{hPa}$ 气温显著增温. 个例分析还发 现 ${ }^{[17]}$, 冬季弱南极涛动会造成春季蒙古气旋活跃, 地面大风增加，从而使我国华北地区春季沙尘天气 频繁发生. 基于 3 4 月南极涛动指数预测我国东部夏 季降水的尝试也得以开展 ${ }^{[18 \sim 20]}$. Sun 等人的一系列工 作还表明, 春季南极涛动不仅对东亚夏季风有重要 影响, 还可以影响到北美季风[21]和西非季风[22].

南海夏季风试验的成果表明, 中南半岛和南海 附近地区是亚洲夏季风最先爆发的区域 ${ }^{[23]}$. 其爆发 是亚洲地区季节转变和雨季来临的一个重要标志. 亚洲夏季风爆发的前兆影响可追溯到春季的索马里 越赤道气流. 在每年的夏季风爆发前, 索马里越赤道 气流会有一次迅速的增强, 有利于加速孟加拉湾地 区西风的向东扩展, 并使控制在南海上空的西太平 洋副高东撤, 促使夏季风爆发. 而前述研究结果也指 出, 南半球的副热带高压与索马里越赤道气流强度 有重要关系 ${ }^{[14]}$, 这就提示我们能否将夏季风爆发的 影响源地继续向南拓延到南半球的高纬度地区(南极 涛动). 另一方面, 每年全国气候预测会商和各类重 大决策服务会议都在 3 4 月开始, 而此时无法获取完 整的春季资料, 这就需要基于冬季环流开展夏季风 爆发预测，这也是本工作的出发点.

\section{1 资料和南极涛动指数}

本文所使用的资料主要为 NCEP/NCAR 逐日和 逐月再分析资料集中的海平面气压场、500 hPa 位势 高度场、 $850 \mathrm{hPa}$ 水平风场和对外长波辐射(OLR), 该 资料水平分辨率为 $2.5^{\circ} \times 2.5^{\circ[24]}$, 时段为 $1979 \sim 2011$ 年. 同时段的南海夏季风爆发日期序列取自国家气 候中心，规定监测区 $\left(10^{\circ} \sim 20^{\circ} \mathrm{N}, 110^{\circ} \sim 120^{\circ} \mathrm{E}\right)$ 平均纬 向风由东风稳定转为西风以及假相当位温稳定地大 于 $340 \mathrm{~K}$ 的时间为南海夏季风爆发的主要指标，同时 参考 200,500 和 $850 \mathrm{hPa}$ 位势高度场的演变.

关于南极涛动指数的定义有两种：一种为南半 球高纬度和副热带的气压梯度, 如 Gong 等人 ${ }^{[25]}$ 将 $40^{\circ}$ 和 $65^{\circ} \mathrm{S}$ 纬圈平均的海平面气压差定义为南极涛 动指数. 考虑到南极涛动中心的较低纬度位置位于 $30^{\circ} \mathrm{S}$ 而非 $40^{\circ} \mathrm{S}$, 同时, 年平均的南半球副热带高压 带的中心脊线及 Ferrel 环流的下沉支均位于 $30^{\circ} \mathrm{S}$, 高 辉 ${ }^{[26]}$ 将该指数定义修订为 $65^{\circ}$ 和 $30^{\circ} \mathrm{S}$ 纬圈平均气压 差的标准化值. 另外一种定义为南半球 $20^{\circ} \mathrm{S}$ 以南位 势高度场的第一模态时间系数 ${ }^{[27]}$. 本文采用第二种 定义, 即南半球热带外 $700 \mathrm{hPa}$ 位势高度场 EOF1 的 时间系数(逐月南极涛动指数值可在 NOAA/CPC 网站 获取).

图 1 是 1980 2012 年冬季(1980 年冬季即 1979 年 12 月至 1980 年 2 月平均)南极涛动指数逐年标准 化序列. 在最近 33 年中, 该指数有明显的上升趋势, 其数值增加的显著性通过 $95 \%$ 置信度 $t$ 检验. 本文选 取指数值超过 1 的 8 年 $(1989,1994,1995,1999,2000$,

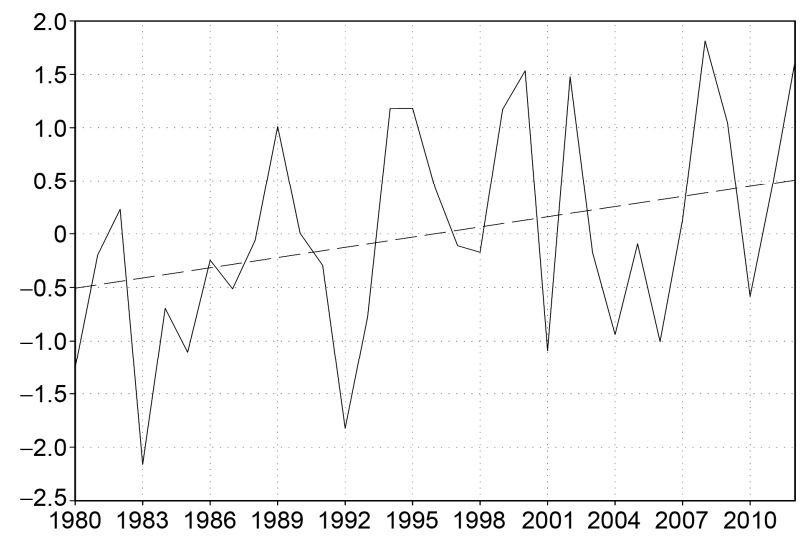

图 1 标准化的冬季(12 2月)南极涛动指数(实线)及其线性趋 势线(虚线)

横坐标为年份, 纵坐标为指数值 
2002,2008 和 2009 年)作为冬季南极涛动偏强年; 选 取指数值低于 -1 的 7 年 $(1980,1983,1985,1992,2001$, 2004 和 2006 年)及 1993 年(指数值为 -0.8 ) 作为冬季南 极涛动偏弱年.

\section{2 冬季南极涛动异常对亚洲夏季风爆发早 晚的影响}

研究表明 ${ }^{[23]}$, 中南半岛和南海是亚洲夏季风最 早爆发的地区. 就气候平均而言, 每年的亚洲夏季风 于第 26 候也即 5 月上旬最早在孟加拉湾东部和中南 半岛率先爆发, 于第 28 候即 5 月中旬在南海地区爆 发. 之后夏季风分别向南亚与西北太平洋传播, 一个 月之后导致整个亚洲-西太平洋夏季风的全面爆发. 下面重点分析南极涛动异常强弱年中南半岛和南海 地区夏季风爆发早晚的异常.

在南极涛动高指数年(图 2), 中南半岛地区的强 对流 (OLR 值低于 $230 \mathrm{~W} / \mathrm{m}^{2}$ ) 最早于 4 月下旬在 $100^{\circ} \mathrm{E}$ 附近率先爆发并迅速向西传播到孟加拉湾东侧. 在 5 月上旬末, 孟湾东侧的局地强对流已低于 $200 \mathrm{~W} / \mathrm{m}^{2}$. 在南海地区, 强对流全面爆发的时间约在 5 月上旬末, 比孟加拉湾偏晚约 2 侯左右. 在南海地区, 纬向西风 稳定建立的时间和强对流爆发时间基本一致，也在 5 月第 2 侯. 由于多年平均的孟加拉湾夏季风爆发时间
约在 5 月第 2 侯，南海夏季风爆发时间为 5 月第 4 侯, 这表明，冬季南极涛动偏强年后期夏季风爆发时间 会偏早. 从国家气候中心逐年南海夏季风监测结果 看, 上述 8 个南极涛动强年后期春季, 有 5 年南海夏 季风的爆发早于 5 月第 4 候.

而在南极涛动偏弱的 8 年中(图 2), 中南半岛地 区的强对流建立时间明显偏晚，直到 5 月初, $100^{\circ} \mathrm{E}$ 附近才出现了 $230 \mathrm{~W} / \mathrm{m}^{2}$ 以下的强对流, 但强度明显 弱于冬季南极涛动强年, 且出现了短暂中断. 200 $\mathrm{W} / \mathrm{m}^{2}$ 以下的强对流直到 5 月下旬才出现. 强对流完 全传播到南海的时间位于 6 月初(图上未能显示). 850 $\mathrm{hPa}$ 纬向风在 5 月下旬初完全转为西风. 和强南极涛 动年不同, 在弱南极涛动年, 后期的强对流爆发时间 和低层纬向风由东风转为西风时间并不一致. 监测 表明, 在南极涛动偏弱的 8 年中, 除 2001 年外, 其他 年份南海夏季风均在 5 月第 4 候及之后爆发.

统计结果还显示, 亚洲夏季风的爆发有明显的 提前趋势. 以南海夏季风为例, 其在最近 20 年的平 均爆发时间比之前时段要提早一候左右, 而从图 1 也 可以看出冬季南极涛动指数的增强趋势(通过 $95 \%$ 置 信度检验)。这表明，二者不仅在年际时间尺度上有 较好的对应关系, 在趋势上也有一致的变化.

除对流和风场外，亚洲夏季风爆发的另外一个
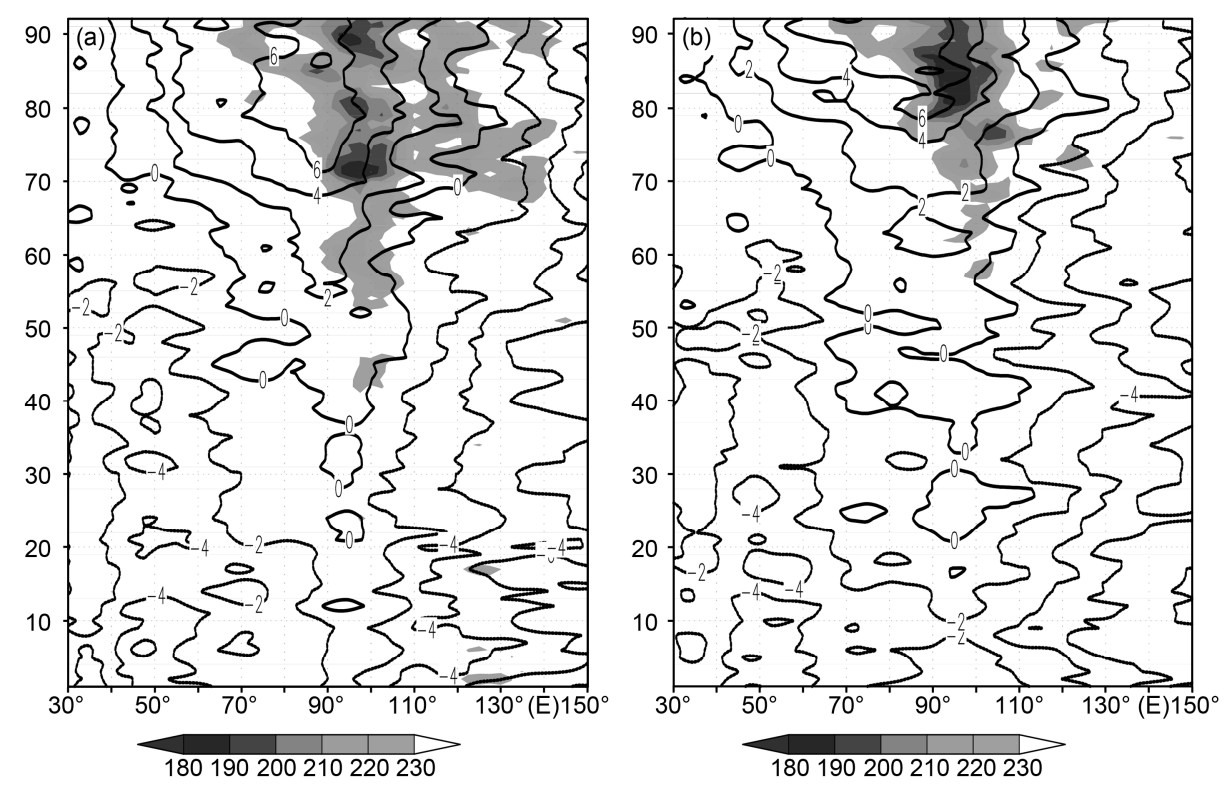

图 2 冬季南极涛动高指数年(a)和低指数年(b)各自合成的 $5^{\circ} \sim 20^{\circ} \mathrm{N}$ 平均的 $850 \mathrm{hPa}$ 纬向风(等值线, 单位: $\mathrm{m} / \mathrm{s}$, 其中粗线条 为风速零线)和 $O L R\left(\right.$ 阴影, 单位: $W / \mathrm{m}^{2}$ )

纵坐标数字 1 表示 3 月 1 日, 2 表示 3 月 2 日, ..., 92 表示 5 月 31 日 
突变特征是西太平洋副高(后文简称为副高)东移撤 出南海. 这在南极涛动异常年份的合成图上也有非 常明显的差异(图略). 在南极涛动强年, 副高强度整 体偏弱, 很难看到 $5880 \mathrm{gpm}$ 以上的位势高度高值区, 即使是 $5870 \mathrm{gpm}$ 等值线也已在 5 月上旬撤离南海东 移至 $120^{\circ} \mathrm{E}$ 以东洋面. 而在南极涛动弱年, 5 月副高 强度整体偏强, 即使在 5 月底, $5870 \mathrm{gpm}$ 等值线还位 于南海上空. 因此, 副高的位置和强度差异也表明了 冬季南极涛动确实对亚洲夏季风爆发早晚有很好的 指示意义.

研究表明 ${ }^{[26]}$, 低层的索马里越赤道气流对夏季 风爆发有至关重要的作用. 在季风爆发前 2 候, 索马 里急流有一次迅速的增强, 从而加速孟加拉湾地区 西风向东扩展, 并使控制在南海上空的副高东撤. 若 索马里越赤道气流建立偏早、强度偏强, 南海夏季风 爆发易偏早. 反之, 当其建立偏晚、强度偏弱时, 季 风爆发易偏晚. 那么, 索马里越赤道气流是否是冬季 南极涛动影响亚洲夏季风爆发早晚的中间过程呢? 图 3 给出了冬季南极涛动指数分别与 3 月和 4 月沿赤 道 $850 \mathrm{hPa}$ 经向风的相关. 在东半球, 越赤道气流主 要位于索马里 $\left(45^{\circ} \mathrm{E}\right.$ 附近 $)$ 、苏门答腊 $\left(85^{\circ} \mathrm{E}\right)$ 、南海 $\left(105^{\circ} \mathrm{E}\right)$ 、西太平洋 $\left(125^{\circ} \mathrm{E}\right)$ 和巴布亚新几内亚 $\left(150^{\circ} \mathrm{E}\right)$. 但在 3 月(图 3 中实线所示), 由于仅有索马里越赤道 气流建立, 因此在图 3 上仅在索马里地区经向风和前 冬南极涛动指数的关系通过 $95 \%$ 置信度检验. 到了 4 月(图 3 中虚线所示), $40^{\circ} \sim 50^{\circ} \mathrm{E}$ 处仍维持一个高相关 中心, 但中心的位置略有东移, 这主要是因为 4 月索 马里越赤道气流的中心轴线也较 3 月略有东移. 在 4 月, 另外一个通过 $95 \%$ 置信度检验的地区位于 $80^{\circ} \sim$ $90^{\circ} \mathrm{E}$ 之间, 即苏门答腊越赤道气流的主体位置. 而 在其他几支越赤道气流处, 经向风强度和冬季南极 涛动的关系并不显著.

对比南极涛动高、低指数年合成的 $850 \mathrm{hPa}$ 沿赤 道经向风可以更清楚看出这种差异(图略). 在冬季南

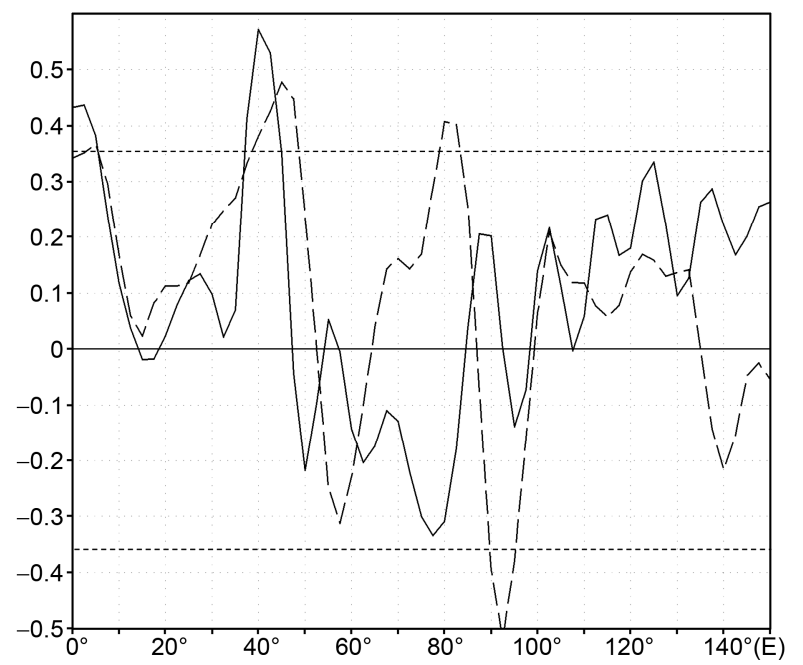

图 3 冬季南极涛动指数分别与 3 月(实线)、4 月(虚线)沿 赤道 $850 \mathrm{hPa}$ 经向风相关

虚线对应为 $95 \%$ 置信度检验标准

极涛动指数强年, $40^{\circ} \sim 60^{\circ} \mathrm{E}$ 平均的经向风约在 4 月中 旬开始全面转为南风, 且稳定维持. 而在弱南极涛动 年, $40^{\circ} \sim 60^{\circ} \mathrm{E}$ 处南风建立不稳定, 多次出现波动, 直 到 5 月初才稳定转为南风风量. 在其他几支越赤道气 流处, 差异不明显. 合成分析的结果和图 3 一致.

由上述分析可知, 冬季南极涛动偏强时, 3 4 月 索马里越赤道气流也将偏强. 而影响孟加拉湾和南 海夏季风爆发的赤道印度洋西风正是主要由索马里 急流越过赤道后在地转偏向力作用下转向形成. 图 4 是冬季南极涛动指数与 4 月 $850 \mathrm{hPa}$ 纬向风相关. 可 以看到, 在北半球热带地区, 印度洋上空是较强的正 相关区，其中 $80^{\circ} \sim 120^{\circ} \mathrm{E}$ 附近都是通过 $95 \%$ 置信度检 验的显著正相关区. 赤道印度洋西风的加强和东传 将加速推动副高东移撤出南海, 并在低层加强辐合 上升，促使对流迅速爆发.

这一影响过程的机制可从图 5 得以解释. 图 5 为 冬季南极涛动指数与 3 月海平面气压场相关. 可见在

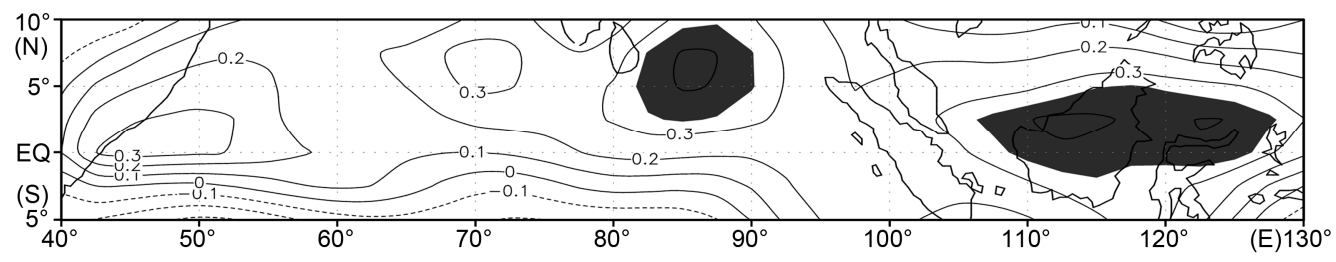

图 4 冬季南极涛动指数与 4 月 $850 \mathrm{hPa}$ 纬向风相关 阴影区通过 $95 \%$ 置信度检验 


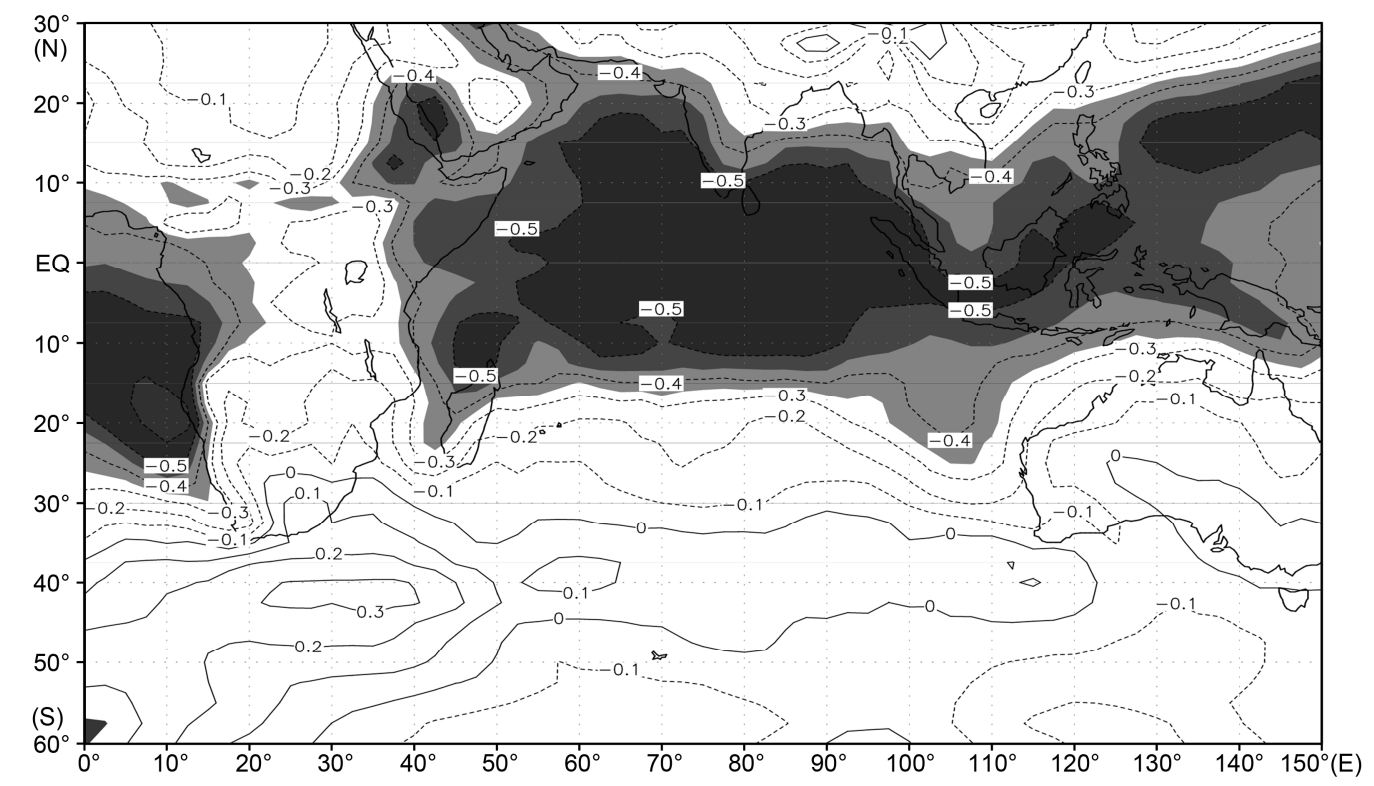

图 5 冬季南极涛动指数与 3 月海平面气压场相关 阴影区通过 $95 \%$ 置信度检验

整个热带地区都是显著的负相关, 而在南半球副热 带地区则为正相关区. 很显然, 这种相关场的配置使 得在强冬季南极涛动年后期初春, 热带地区的赤道 辐合带加深, 南半球副热带地区的高压带加强, 从而 加大了南半球副热带和热带地区的气压梯度力, 这 是造成索马里越赤道气流在 3 4 月加强的直接原因. 而当冬季南极涛动偏弱时, 副热带和热带之间的气 压梯度力减弱, 导致索马里急流也偏弱.

除南极涛动外, ENSO 是另一个对亚洲夏季风起 着主导作用的外强迫因子. 为了更好地对比二者对 夏季风爆发早晚的贡献, 计算了研究时段内各自偏 相关系数, 结果表明, 在不考虑南极涛动影响下, 冬 季 Niño3.4 区海温与南海夏季风爆发日期的偏相关系 数为 0.05 , 而在不考虑 ENSO 影响下, 冬季南极涛动 与南海夏季风爆发日期的偏相关系数为 -0.17 , 虽然 也未通过 95\%置信度检验, 但明显高于前者, 表明对 亚洲夏季风爆发早晚影响而言, 南极涛动的作用要 强于 ENSO. 初步的分析表明, 在冬季南极涛动强年, 热带太平洋海温体现出一定的准拉尼娜特性, 但南 太平洋(尤其是澳大利亚东侧)至海洋大陆地区海温 异常不很明显. 本文主要从印度洋上空环流变化的 角度分析了这种影响机制, 但南极涛动的异常是否 会影响到太平洋地区的海温分布从而改变亚洲地区 春季海陆温差的季节性反转进程并进而影响夏季风
爆发早晚? 这部分工作还需要进一步深人讨论.

\section{3 主要结论}

统计分析表明, 冬季南极涛动影响亚洲夏季风 爆发早晚的初步过程和机理可表述为, 当冬季南极 涛动偏强时, 由于南半球副热带和高纬度地区气压 呈跷踾板变化特征, 且高纬度环流异常具有较好的 冬春持续性, 导致 3 月中纬度马斯克林高压和澳大利 亚高压也偏强, 而在热带地区气压场偏低(赤道辐合 带偏深), 造成南半球中纬度和热带地区气压梯度力 加大, 加强了索马里越赤道气流. 而索马里急流增强 并越过赤道后, 受科氏力作用, 热带印度洋西风也加 强, 有利于低层辐合的加强和对流的活跃, 并使副高 偏弱且较早东移撤出南海, 使中南半岛和南海夏季 风爆发偏早. 反之, 当冬季南极涛动偏弱时, 南半球 副热带和热带之间的气压梯度力偏小, 索马里越赤 道气流在 3 4 月偏弱, 赤道印度洋西风也偏弱, 孟加 拉湾和南海对流偏弱, 南海上空副高偏强且东撤时 间偏晚, 造成东亚夏季风爆发偏晚.

过去的大量研究结果表明, 亚洲夏季风爆发早 晚可追溯到春季南半球热带和副热带大气环流异常. 但由于每年全国汛期气候预测会商在 3 月开始, 此时 春季资料尚不完整, 上述环流异常程度也不明确, 给 业务应用带来了一定困难. 本文则进一步分析了这 
种影响，指出在空间上这种影响源地可以追溯到南 半球的高纬度地区，即南极涛动异常，而在时间上可
拓延至冬季. 因此, 冬季的南极涛动强度异常可作为 亚洲夏季风爆发的一个新前兆信号.

\section{参考文献}

1 Walker G T. World weather. Quart J Res Meteorol Soc, 1928, 54: 79-87

2 Montgomery R B. Report on the work of G. T. Walker. Mon Weather Rev, 1940, 39: 1-22

3 Van Loon H. The half-yearly oscillations in middle and high southern latitudes and the coreless winter. J Atmos Sci, 1967, 24: 472-486

4 Rogers J C, Van Loon H. Spatial variability of sea level pressure and $500 \mathrm{mb}$ height anomalies over the Southern Hemisphere. Mon Weather Rev, 1982, 110: 1375-1392

5 Mo K C, White G N. Teleconnections in the Southern Hemisphere. Mon Weather Rev, 1985, 113: 22-37

6 陶诗言, 徐淑英, 郭其蕴. 夏季东亚热带和副热带地区经向和纬向环流型的特征. 气象学报, 1962, 32: 91-103

7 陈隆勋. 东亚季风环流系统的结构及其中期变动. 海洋学报, 1984, 6: 744-758

8 王绍武, 赵宗慈. 长期天气预报基础. 上海：上海科学技术出版社, 1987. 201

9 黄士松, 汤明敏. 西北太平洋和南印度洋上环流系统的中期振荡与遥相关. 气象科学, 1988, 8: 1-13

10 杨修群, 黄士松. 马斯克林高压的强度变化对大气环流影响的数值试验. 气象科学, 1989, 9: 125-137

11 何金海, 陈丽臻. 南半球中纬度准 40 天振荡及其与北半球夏季风的关系. 南京气象学院学报, 1989, 12: 11-18

12 王会军, 薛峰. 索马里急流的年际变化及其对半球间水汽输送和东亚夏季降水的影响. 地球物理学报, 2003, 46: 18-25

13 薛峰, 林一骅, 曾庆存. 论大气环流的季节划分和季节突变, Ш气候平均情况. 大气科学, 2002, 26: 308-314

14 薛峰, 王会军, 何金海. 马斯克林高压和澳大利亚高压的年际变化及其对东亚夏季风降水的影响. 科学通报, 2003, 48: 287-291

15 范可, 王会军. 南极涛动的年际变化及其对东亚冬春季气候的影响. 中国科学 D 辑：地球科学, 2006, 36: 385-391

16 范可, 王会军. 南极涛动异常及其对冬春季北半球大气环流影响的数值模拟试验. 地球物理学报, 2007, 50: 397-403

17 范可, 王会军. 异常弱的南极涛动和 2006 年我国春季沙尘气候形势. 气候与环境研究, 2007, 12: 475-480

18 范可, 王会军. 南极涛动异常与 2006 年我国东部夏季降水形势预测. 应用气象学报, 2006, 17: 383-384

19 范可, 王会军, Choi Young-Jean. 一个长江中下游夏季降水的物理统计预测模型. 科学通报, 2007, 52: 2900-2905

20 Sun J Q, Wang H J, Yuan W. A possible mechanism for the co-variability of the boreal spring Antarctic Oscillation and the Yangtze River valley summer rainfall. Int J Climatol, 2009, 29: 1276-1284

21 Sun J Q. Possible impact of the boreal spring Antarctic oscill ation on the north American summer monsoon. Atmos Ocean Sci Lett, 2010, 3: $232-236$

22 Sun J Q, Wang H J, Yuan W. Linkage of the boreal spring Antarctic oscillation to the West African summer monsoon. J Meteorol Soc Jpn, 2010, 88: 15-28

23 丁一汇, 李崇银, 何金海, 等. 南海夏季风试验与东亚夏季风. 气象学报, 2004, 62: 561-586

24 Kalnay E, Kanamitsu M, Kistler R, et al. The NCEP/NCAR 40-year reanalysis project. Bull Amer Meteorol Soc, 1996, 77: 437-471

25 Gong D Y, Wang S W. Definition of Antarctic oscillation index. Geophys Res Lett, 1999, 26: 459-462

26 高辉. 南半球大气环流的季节和年际变化及其对东亚夏季风的影响. 博士学位论文. 南京: 南京信息工程大学, 2004. 162

27 Thompson D W J, Wallace J M. Annular modes in the extratropical circulation, Part I: Month-to-month variability. J Clim, 2000, 13: 1000-1016 